\title{
The Implementation of a Multi-institutional Multidisciplinary Simulation-based Resuscitation Skills Training Curriculum
}

\author{
Timothy Chaplin ${ }^{1}$, Rylan Egan ${ }^{2}$, Nicholas Cofie ${ }^{3}$, Jeffrey JJ Gu ${ }^{4}$, Tamara McColl ${ }^{5}$, Brent Thoma 6 \\ 1. Emergency Medicine, Queen's University, Kingston, CAN 2. Medical Education and Simulation, Queen's University, \\ Kingston, CAN 3. Miscellaneous, Queen's University, Kingston, CAN 4. Surgery, University of Saskatchewan, \\ Saskatoon, CAN 5. Emergency Medicine, University of Manitoba, Winnipeg, CAN 6. Emergency Medicine, University of \\ Saskatchewan, Saskatoon, CAN
}

Corresponding author: Timothy Chaplin, chaplintim2@gmail.com

\begin{abstract}
Competency-based curricula require the development of novel simulation-based programs focused on the assessment of entrustable professional activities. The design and delivery of simulation-based programs are labor-intensive and expensive. Furthermore, they are often developed by individual programs and are rarely shared between institutions, resulting in duplicate efforts and the inefficient use of resources.
\end{abstract}

The purpose of this study is to demonstrate the feasibility of implementing a previously developed simulation-based curriculum at a second institution. We sought to demonstrate comparable program-level outcomes between our two study sites.

A multi-disciplinary, simulation-based, resuscitation skills training curriculum developed at Queen's University was implemented at the University of Saskatchewan. Standardized simulation cases, assessment tools, and program evaluation instruments were used at both institutions.

Across both sites, 87 first-year postgraduate medical trainees from 14 different residency programs participated in the course and the related research. A total of 226 simulated cases were completed in over 80 sessions. Program evaluation data demonstrated that the instructor experience and learner experience were consistent between sites. The average confidence score (on a 5-point scale) across sites for resuscitating acutely ill patients was 3.14 before the course and $4.23(p<0.001)$ after the course.

We have described the successful implementation of a previously developed simulation-based resuscitation curriculum at a second institution. With the growing need for competency-based instructional methods and assessment tools, we believe that programs will benefit from standardizing and sharing simulation resources rather than developing curricula de novo.

Received 09/17/2018

Review began 10/07/2018

Review ended 10/31/2018

Published 11/14/2018

(๑) Copyright 2018

Chaplin et al. This is an open access article distributed under the terms of the Creative Commons Attribution License CC-BY 3.0., which permits unrestricted use, distribution, and reproduction in any medium, provided the original author and source are credited.
Categories: Medical Education, Medical Simulation

Keywords: simulation, resuscitation, medical education, curriculum development

\section{Introduction}

Postgraduate medical education programs in Canada and the United States are transitioning or have transitioned to competency-based medical education (CBME) models that incorporate national milestones and entrustable professional activities (EPAs) [1-2]. One of the challenges of implementing CBME is that it requires direct observation and demonstration of competence of stage-specific EPAs before progressing in training. Resuscitation-based EPAs are particularly difficult to assess because of their unpredictable occurrence and resulting lack of reliable direct observation [3-4]. Simulation can assist with these challenges by providing safe and reproducible experiences while also allowing expert observation, focused feedback, and deliberate practice [5]. Unfortunately, the development of simulation curricula requires considerable resources and many programs have a limited number of faculty with formal simulation training. Moreover, simulation curricula are traditionally developed at the individual residency program level and are rarely shared within or between teaching institutions.

The emerging number of online sources of free open access medical education material and published simulation cases is slowly targeting this problem. There are numerous websites and repositories that provide access to cases that have been used elsewhere and, in some instances, even peer-reviewed (MedEdportal.org, EMSimcases.com). However, these cases are rarely part of a comprehensive curriculum, often do not contain assessment tools linking them to specific EPAs or milestones, and frequently lack program evaluation instruments.

The objective of this report is to demonstrate the feasibility of adopting a simulation curriculum, including 


\section{Cureus}

well-designed peer-reviewed cases, competency-based assessment tools tied to EPAs, and program evaluation instruments, between two institutions and multiple residency programs while demonstrating comparable program level outcomes.

\section{Materials And Methods}

The "Nightmares Course” at Queen's University is a resuscitation skill training program that has been previously described [6]. The Nightmares program facilitates the challenging transition that all medical trainees encounter as they progress from medical students to postgraduate trainees with independent patient-care responsibilities [7]. The initial approach to a critically ill patient is a common source of anxiety at this stage of training and carries significant risk for the patient if not managed competently [8]. The curriculum is designed specifically to teach and assess the following EPA: "Recognizes an acutely unwell floor patient, calls for appropriate help and initiates a basic assessment and management plan.” The University of Saskatchewan sought to create a similar curriculum and contacted educators at Queen's University. In a discussion between the two sites, it was determined that not only could the University of Saskatchewan adopt the Queen's University curriculum, but that the same assessment and program evaluation instruments could be used across both sites. This study was approved by the Research Ethics Boards at Queen's University and the University of Saskatchewan.

\section{Settings and participants}

Course participants in the 2017-2018 academic year included first-year postgraduate medical trainees who were responsible for in-patient call at the University of Saskatchewan and Queen's University. Participation was mandatory and designated as protected academic time by all programs involved. Written consent was requested in order to use assessment data for research purposes.

\section{Curricular design}

In keeping with adult learning theory and principles of assessment within CBME, the curriculum utilized small group learning, spaced repetition, direct observation with immediate formative feedback, and assessment tools anchored to the course EPA [9].

Scenarios for the course were chosen based on the most common calls to the Kingston Health Sciences Centre's Rapid Assessment of Critical Events Team for acutely unwell patients (Table 1). The trainees were instructed to behave as they would if they were the first physician called to assess an acutely unwell patient in the ward at night. Consultants and/or senior trainees were available on the phone when requested.

\begin{tabular}{|c|c|}
\hline 1 & Acute pulmonary edema \\
\hline 2 & Pneumonia \\
\hline 3 & Pulmonary embolism \\
\hline 4 & Bradycardia \\
\hline 5 & Hypertensive emergency \\
\hline 6 & Seizure \\
\hline 7 & Ventricular tachycardia \\
\hline 8 & Hyperkalemia \\
\hline 9 & Sepsis \\
\hline 10 & Acute myocardial infarction \\
\hline 11 & Anaphylaxis \\
\hline 12 & Opiate intoxication \\
\hline
\end{tabular}

\section{TABLE 1: Simulation Scenarios}

Simulation sessions took place between August and December 2017. Over this period, trainees participated in one session every four weeks in groups of four to six. Each simulation session was 90-180 minutes long and involved three or four simulated scenarios. Scenarios lasted for 10-15 minutes and took place in a simulation suite using a high-fidelity mannequin that was set up and operated by a simulation technician. A nurse acted as a confederate in the simulation suite and one or two faculty facilitators observed the scenario 


\section{Assessment of trainees}

The "Nightmares Course" assessment of trainees was modified for implementation at both sites [6]. Trainees were assessed in several ways using the same terminology and entrustment scoring tools (Appendix 1). Before the start of the course, each trainee completed a general confidence score related to managing an acutely unwell patient (Appendix 2). The same score was repeated upon completion of the resuscitation curriculum.

Trainees were assessed during the course in a multisource fashion. After each simulated scenario, the leader was assessed by their peers, a nursing staff, and the attending physician(s) (Appendix 1). The leader also completed a scenario-specific self-entrustment assessment upon reading the case "stem" (Appendix 3) and again after leading the simulated case. The whole assessment was designed as a single five-point entrustment score [10] that was anchored to the course EPA, as well as a box with the heading "please explain your rating" for qualitative comments.

\section{Institutional-specific methods: University of Saskatchewan}

Scenarios were delivered at two sites - Saskatoon and Regina, depending on the location of each trainee. All sessions were conducted using a high-fidelity simulation mannequin, but the model differed between Saskatoon (SimMan 3G, Laerdal, Toronto, Canada) and Regina (Hal S3000 Tetherless Patient Simulator, Gaumard, Florida, USA). Twenty-three faculty credentialed in Anesthesia, Emergency Medicine, General Surgery, Internal Medicine, and Intensive Care Medicine were trained to conduct the simulation sessions. All facilitators were required to complete a simulation and debriefing course as part of taking on this role.

\section{Institutional-specific methods: Queen's University}

All scenarios were delivered at Queen's University using a high-fidelity simulation mannequin (SimMan Essential, Laerdal, Toronto, Canada). A group of 10 faculty facilitators credentialed in Anesthesia, Emergency Medicine, General Surgery, Intensive Care Medicine, and Internal Medicine conducted the simulation sessions and completed the entrustment scores for each scenario. All facilitators had a selfidentified interest in simulation-based teaching and resuscitation.

\section{Program evaluation}

Anonymous feedback from trainees was gathered using a modified version of a previously validated tool: the Evaluation of Technology-Enhanced Learning Materials: Learner Perceptions (ETELM-LP) inventory. Basic demographic data were collected with this survey including age, residency training program, and previous simulation experience. Faculty completed a modified version of the Evaluation of TechnologyEnhanced Learning Materials: Instructor Perceptions (ETELM-IP) inventory. Basic demographic data, including age, sex, and specialty area, were collected along with the program evaluation. For both program evaluation surveys, modifications included the removal of questions that were not relevant to the course, altering the wording of questions to better fit the course, and adding additional questions related to the course objectives.

\section{Results}

\section{Participant demographics}

A total of 87 first-year postgraduate medical trainees from 14 different training programs participated in the resuscitation curriculum and provided written consent for their assessment data to be used for research purposes. Thirty-four trainees were from the University of Saskatchewan and 53 from Queen's University (Table 2). 


\section{Cureus}

\begin{tabular}{|c|c|c|c|}
\hline & & Queen's University & University of Saskatchewan \\
\hline \multirow{3}{*}{ Gender } & Male & 29 & 23 \\
\hline & Female & 21 & 11 \\
\hline & Other & 0 & 0 \\
\hline \multirow{4}{*}{ Age } & $<25$ & 14 & 16 \\
\hline & $26-30$ & 33 & 14 \\
\hline & $31-35$ & 3 & 3 \\
\hline & $>36$ & 0 & 1 \\
\hline \multirow{14}{*}{ Residency Program } & Anatomic Pathology & 2 & 0 \\
\hline & Anesthesia & 4 & 5 \\
\hline & Diagnostic Radiology & 3 & 0 \\
\hline & Emergency Medicine & 0 & 2 \\
\hline & General Surgery & 4 & 4 \\
\hline & Internal Medicine & 23 & 23 \\
\hline & Neurology & 2 & 0 \\
\hline & Ophthalmology & 2 & 0 \\
\hline & Orthopedic Surgery & 3 & 0 \\
\hline & Obstetrics and Gynecology & 3 & 0 \\
\hline & Physiatry & 2 & 0 \\
\hline & Psychiatry & 4 & 0 \\
\hline & Radiation Oncology & 2 & 0 \\
\hline & Urology & 1 & 0 \\
\hline \multicolumn{2}{|l|}{ Total } & 53 & 34 \\
\hline
\end{tabular}

\section{TABLE 2: Participant Demographics}

\section{Assessment of trainees}

A total of 226 cases were conducted across both sites, 93 at Queen's University and 133 at the University of Saskatchewan. Fifty-nine of 87 trainees (68\%) led a scenario and received feedback on their performance. Following a scenario, the leader received an average of 7.5 assessments: one from each of faculty and nursing staff, a self-assessment, and three to five peer assessments. Qualitative comments were included on $84 \%$ of assessments.

\section{Program evaluation}

Thirty-three of 34 trainees at the University of Saskatchewan, and 47 of 53 at Queen's University completed the ETELM-LP (Table 3). A clerical error resulted in the deletion of three questions from the survey at Queen's University; these correspond to the blank rows in Table 3. Agreement with statements was ranked using a 7-point Likert scale, ranging from strongly disagree (1) to strongly agree (7). Notably, the following statements received average scores of 6.2, 6.0, and 6.0, respectively: "Course objectives were relevant to my needs," "I received adequate feedback on my learning progress," and "Overall, the course improved my ability to assess and manage the acutely unwell floor patient." Across both sites, the average confidence score before the course was 3.14, following the course, this was $4.23(p<0.001)$. Institution-specific precourse confidence scores for the University of Saskatchewan and Queen's University were 3.00 and 3.26, respectively, and post-course confidence scores were 4.12 and 4.33 , respectively $(p<0.001$ for both comparisons). 


\section{Cureus}

\begin{tabular}{|c|c|c|}
\hline & $\begin{array}{l}\text { Queen's } \\
\text { University }\end{array}$ & $\begin{array}{l}\text { University of } \\
\text { Saskatchewan }\end{array}$ \\
\hline Instructions provided a good introduction to the course. & 6.0 & 6.1 \\
\hline Course objectives, expectations, and policies were clearly stated. & 5.7 & 5.9 \\
\hline The course was well organized. & 6.3 & 6.4 \\
\hline Course objectives were relevant to my needs. & 6.2 & 6.2 \\
\hline The course technologies supported the learning objectives. & 6.4 & 6.3 \\
\hline The educational activities promoted the achievement of the course objectives. & 6.2 & 6.2 \\
\hline There was a strong instructor presence/personal touch in the course. & & 6.1 \\
\hline Educational activities encouraged interaction and collaboration with other participants. & 6.3 & 6.3 \\
\hline $\begin{array}{l}\text { Requirements for interaction and collaboration with other participants were clearly } \\
\text { articulated. }\end{array}$ & 5.7 & 6.2 \\
\hline $\begin{array}{l}\text { Face-to-face activities contributed meaningfully toward achieving the course learning } \\
\text { objectives. }\end{array}$ & 6.3 & 6.2 \\
\hline Assessments were appropriate for the course objectives, content, and activities. & 6.0 & 5.8 \\
\hline I had sufficient opportunity to assess and reflect upon my learning progress. & 5.7 & 5.9 \\
\hline I received adequate feedback on my learning progress. & 5.1 & 6.0 \\
\hline I had sufficient opportunity to evaluate/provide feedback on the course. & 6.0 & 6.2 \\
\hline I received adequate support for any technical issues encountered during this course. & 5.7 & 5.9 \\
\hline $\begin{array}{l}\text { I received adequate support for any questions or concerns that I had about my } \\
\text { learning. }\end{array}$ & 5.9 & 6.0 \\
\hline This course will change my practice. & 6.1 & 6.0 \\
\hline Providing feedback to my peers helped me to enhance my own performance. & 5.8 & 5.5 \\
\hline Receiving feedback from my peers helped me to enhance my own performance & 5.6 & 5.7 \\
\hline Receiving feedback from the nurse helped me to enhance my own performance & & 5.7 \\
\hline Receiving feedback from the attending helped me to enhance my own performance & & 6.3 \\
\hline Assessing my own performance helped me to enhance my performance. & 5.8 & 5.7 \\
\hline I was satisfied with the length of time spent on the course. & 5.7 & 5.7 \\
\hline I was satisfied with the overall effectiveness of the instructors. & 6.4 & 6.2 \\
\hline $\begin{array}{l}\text { I think my performance in the simulation lab is representative of my clinical ability in } \\
\text { the 'real world'. }\end{array}$ & 5.3 & 5.2 \\
\hline I was satisfied with the overall quality of the course. & 6.2 & 6.2 \\
\hline I would recommend this course to other PGY-1 residents. & 6.6 & 6.2 \\
\hline $\begin{array}{l}\text { Overall, the course improved my ability to assess and manage the acutely unwell floor } \\
\text { patient. }\end{array}$ & 6.5 & 6.0 \\
\hline
\end{tabular}

\section{TABLE 3: Evaluation of Technology-enhanced Learning Materials: Learner Perceptions}

Agreement ranked on a 7-point Likert scale

Twenty-two of 23 faculties at the University of Saskatchewan and 11 of 11 at Queen's University completed the ETELM-IP (Table 4). Notably, using a similar 7-point Likert scale, the following statements received average scores of 6.3, 6.5, and 5.9, respectively: "the educational activities encouraged participants' engagement with course content," "I was satisfied with the overall quality of the course," and "I provided 
adequate feedback on residents' learning progress.”

\begin{tabular}{|c|c|c|}
\hline & $\begin{array}{l}\text { Queen's } \\
\text { University }\end{array}$ & $\begin{array}{l}\text { University of } \\
\text { Saskatchewan }\end{array}$ \\
\hline Instructions provided a good introduction to the course & 6.2 & 6.0 \\
\hline Course objectives were relevant to participant needs. & 6.5 & 6.3 \\
\hline The course technologies supported the learning objectives. & 6.5 & 6.4 \\
\hline $\begin{array}{l}\text { The educational activities encouraged participants' engagement with course materials / } \\
\text { content. }\end{array}$ & 6.4 & 6.3 \\
\hline The educational activities promoted participants' achievement of the course objectives. & 6.3 & 6.2 \\
\hline I was able to contribute a personal presence / personal touch during the course's delivery. & 6.4 & 6.3 \\
\hline Educational activities encouraged participants' interaction and collaboration. & 6.6 & 6.5 \\
\hline $\begin{array}{l}\text { Face-to-face activities contributed meaningfully toward achieving the course learning } \\
\text { objectives. }\end{array}$ & 6.5 & 6.4 \\
\hline $\begin{array}{l}\text { Assessments (e.g., tests and self-assessments) were appropriate for the course objectives, } \\
\text { content, and activities. }\end{array}$ & 5.4 & 5.5 \\
\hline I provided adequate feedback on residents' learning progress. & 5.7 & 5.9 \\
\hline Learner assessments and provision of feedback proceeded smoothly. & 5.4 & 5.9 \\
\hline The course will be easy to maintain and deliver again. & 6.0 & 6.2 \\
\hline I had access to needed tools during course delivery. & 5.8 & 6.2 \\
\hline $\begin{array}{l}\text { I received adequate support for any technical issues encountered while developing and } \\
\text { delivering this course. }\end{array}$ & 6.2 & 6.3 \\
\hline $\begin{array}{l}\text { I was able to provide adequate support to students for questions or concerns about their } \\
\text { learning. }\end{array}$ & 6.0 & 6.2 \\
\hline The course was a good use of time and resources. & 6.4 & 6.3 \\
\hline I was satisfied with the overall quality of the course. & 6.5 & 6.5 \\
\hline
\end{tabular}

TABLE 4: Evaluation of Technology-enhanced Learning Materials: Instructor Perceptions

Agreement ranked on a 7-point Likert scale

\section{Discussion}

This paper addresses a current and growing challenge in postgraduate medical education. Namely, the development and distribution of competency-based curricula designed to teach and assess EPAs that are not well suited to a clinical-based model. Moreover, CBME requires that postgraduate training programs directly observe the abilities of their trainees and provide them with formative feedback, even for rare and unpredictable EPAs. Developing simulation-based curricula to address these challenges will require significant resources. Instead of creating simulation curricula de novo within each training program or institution, we believe that certain EPAs and their instructional and assessment methods are well-suited for widespread distribution.

In addition to the efficiency rationale for using established curricula and their programs of assessment, there is a tremendous potential for scholarship. The small sample size is very often a limitation of educational research. The use of similar curricula and assessment tools at different institutions allows for a more robust synthesis of data for research purposes. The implementation of a common curriculum at a second institution has effectively doubled our subject numbers and will allow analyses that were not previously possible.

This paper describes the comprehensive and successful transfer of a resuscitation curriculum to a second institution. To facilitate further adoption of this curriculum, we plan to make it readily available online. The simulation cases used for the program will be peer-reviewed and published on EMSimCases.org using their 
standardized template. A blog post published on the site will provide an overview of the simulation program and allow the faculty from other institutions to access the curriculum and course-specific assessment and program evaluation tools.

The costs associated with this curriculum were $\$ 120$ per session at Queen's University and $\$ 96$ per session at the University of Saskatchewan. This amount paid the nursing confederate and simulation technician salaries. Additional costs included faculty time and the use of the simulation laboratory. At Queen's University, faculties receive "teaching points" for their respective departments and access to the simulation laboratory was granted through the Office of Postgraduate Medical Education. At the University of Saskatchewan, faculties are paid variable rates depending on their respective agreements with the College of Medicine and access to the simulation laboratory was funded via block payments to the simulation centers by the College of Medicine.

\section{Conclusions}

We have demonstrated the feasibility of transposing a multi-disciplinary simulation-based resuscitation curriculum from one institution to another, including cases, assessment tools, and program evaluation instruments. We hope this example of successful curricular adaptation will encourage other institutions and departments to foster collaboration in future curriculum development and scholarship.

\section{Appendices}

Trainee:

Date of Assessment (DD/MM/YY):

Assessed by:

In the scenario that was just completed, to what degree would you have had to help the resident recognizt an acutely unwell patient, call for appropriate help, and initiate a basic assessment and management plan

Clinical Context $($ Case $)=$

\begin{tabular}{|c|c|}
\hline \multicolumn{2}{|l|}{ Primary Assessment } \\
\hline $\begin{array}{l}\text { - Ensures monitors are applied \& vital signs obtained (incl } \\
\text { glucose + Temp) } \\
\text { - Establishes appropriate vascular access } \\
\text { - Conducts a focused assessment of airway \& breathing }\end{array}$ & $\begin{array}{l}\text { - Assesses level of consciousness/disability } \\
\text { - Simultaneously performs initial diagnostic \& initial } \\
\text { therapeutic/resuscitative actions } \\
\text { - Allocates \& utilizes resources appropriately }\end{array}$ \\
\hline
\end{tabular}

\begin{tabular}{|ll|}
\hline Diagnostic Actions \\
\hline $\begin{array}{l}\text { Performs a targeted history \& physical exam } \\
\text { Exposes the patient appropriately to complete exam }\end{array}$ & $\bullet \begin{array}{l}\text { Performs rhythm analysis/ECG as indicated } \\
\text { Orders appropriate blood work }\end{array}$ \\
\hline
\end{tabular}

\begin{tabular}{|ll|}
\hline Therapeutic Actions & \\
\hline - Prioritizes critical or time sensitive therapies & - Orders IV fluids or blood products as appropriate \\
- Performs/directs necessary resuscitative maneuvers & - Orders appropriate medications as required \\
\hline
\end{tabular}

\begin{tabular}{|c|c|}
\hline Communication & \\
\hline $\begin{array}{l}\text { - Uses clear, directed, closed loop communication } \\
\text { - Clearly assigns \& articulates leadership } \\
\quad \text { Shares mental model \& verbalizes priorities }\end{array}$ & $\begin{array}{l}\text { - Solicits opinion from team members, experts, \& consultants as } \\
\quad \text { needed } \\
\text { - Involves patient \& family in decision-making } \\
\text { - Prepares \& debriefs team as time permits }\end{array}$ \\
\hline
\end{tabular}

\begin{tabular}{|c|c|c|c|c|}
\hline \multicolumn{5}{|c|}{ ENTRUSTMENT DECISION } \\
\hline$\underbrace{}_{1}$ & $\begin{array}{c}0 \\
2 \\
\text { I had to talk them } \\
\text { through }\end{array}$ & $\begin{array}{c}0 \\
3 \\
\text { I needed to } \\
\text { prompt }\end{array}$ & $\begin{array}{c}0 \\
4 \\
\text { Ineeded to be } \\
\text { there just in case }\end{array}$ & $\begin{array}{c}0 \\
\text { I didn't need to be } \\
\text { there }\end{array}$ \\
\hline
\end{tabular}

PLEASE EXPLAIN YOUR RATING:

FIGURE 1: Generic Assessment Tool (Appendix 1) 


\section{Cureus}

Trainee:

Date (DD/MM/YYYY):

If you were called to assess an acutely unwell patient ...

To what degree do you feel that your Attending would have to help you recognize the acutely unwell patient, call for appropriate help, and initiate a basic assessment and management plan?

\begin{tabular}{|c|c|c|c|c|}
\hline $\begin{array}{c}\text { O } \\
\text { They would have } \\
\text { to do }\end{array}$ & $\begin{array}{c}\text { O } \\
2 \\
\text { They would have } \\
\text { to talk me through }\end{array}$ & $\begin{array}{c}\text { O } \\
3 \\
\text { They would have } \\
\text { to prompt }\end{array}$ & $\begin{array}{c}\text { O } \\
\text { They would have } \\
\text { to be there just in } \\
\text { case }\end{array}$ & $\begin{array}{c}\text { O } \\
5 \\
\text { They would not } \\
\text { have to be there }\end{array}$ \\
\hline
\end{tabular}

\section{PLEASE EXPLAIN YOUR RATING:}

FIGURE 2: General Confidence Score (Appendix 2)

You are called to assess a $68 \mathrm{M}$ who is acutely short of breath. He is scheduled for an operation later today. He has a history of a myocardial infarction, congestive heart failure (Ejection Fraction 30\%) and COPD.

After reading the stem above, how much supervision do you anticipate you will need from your attending?

\begin{tabular}{|c|c|c|c|c|}
\hline $\begin{array}{c}\text { O } \\
\text { They would have } \\
\text { to do }\end{array}$ & $\begin{array}{c}\text { O } \\
2 \\
\text { They would have } \\
\text { to talk me through }\end{array}$ & $\begin{array}{c}\text { O } \\
3 \\
\text { They would have } \\
\text { to prompt }\end{array}$ & $\begin{array}{l}\text { O } \\
\text { They would have } \\
\text { to be there just in }\end{array}$ & $\begin{array}{c}\text { O } \\
5 \\
\text { They would not } \\
\text { have to be there }\end{array}$ \\
\hline
\end{tabular}

PLEASE EXPLAIN YOUR RATING

FIGURE 3: Case-specific Confidence Score Example (Appendix 3)

\section{Additional Information}

\section{Disclosures}

Human subjects: Consent was obtained by all participants in this study. Queen's University Health Sciences and Affiliated Teaching Hospitals Research Ethics Board, and the University of Saskatchewan's Behavioural Research Ethics Board issued approval N/A. This study was approved by the Research Ethics Boards at Queen's University and the University of Saskatchewan. . Animal subjects: All authors have confirmed that this study did not involve animal subjects or tissue. Conflicts of interest: In compliance with the ICMJE uniform disclosure form, all authors declare the following: Payment/services info: This study was supported by two grants: 1. The College of Medicine Research Award (CoMRAD) for 23,457 Canadian dollars. 2. The Central Region on Educational Affairs of the Association of American Medical Colleges Award for 5000 Canadian dollars. . Financial relationships: All authors have declared that they have no financial 
relationships at present or within the previous three years with any organizations that might have an interest in the submitted work. Other relationships: All authors have declared that there are no other relationships or activities that could appear to have influenced the submitted work.

\section{References}

1. Ten Cate O: Nuts and bolts of entrustable professional activities . I Grad Med Educ. 2013, 5:157-158. 10.4300/JGME-D-12-00380.1

2. Frank JR, Snell LS, Ten Cate O, et al.: Competency-based medical education: theory to practice. Med Teach. 2010, 32:638-645. 10.3109/0142159X.2010.501190

3. Dijksterhuis MG, Voorhuis M, Teunissen PW, Schuwirth LWT, Ten Cate OTJ, Braat DDM, Scheele F: Assessment of competence and progressive independence in postgraduate clinical training . Med Educ. 2009, 43:1156-1165. 10.1111/j.1365-2923.2009.03509.x

4. Holmboe ES: Realizing the promise of competency-based medical education . Acad Med. 2015, 90:411-413. 10.1097/ACM.0000000000000515

5. Issenberg SB, McGaGhie WC, Petrusa ER, Gordon DL, Scalese RJ: Features and uses of high-fidelity medical simulations that lead to effective learning: a BEME systematic review. Med Teach. 2005, 27:10-28. 10.1080/01421590500046924

6. McMurray L, Hall AK, Rich J, Merchant S, Chaplin T: The Nightmares course: a longitudinal, multidisciplinary, simulation-based curriculum to train and assess resident competence in resuscitation. I Grad Med Educ. 2017, 9:503-508. 10.4300/JGME-D-16-00462.1

7. Inaba K, Recinos G, Teixeira PG, et al.: Complications and death at the start of the new academic year: is there a July phenomenon?. J Trauma. 2010, 68:19-22. 10.1097/TA.0b013e3181b88dfe

8. van Walraven C, Jennings A, Wong J, Forster AJ: Influence of house-staff experience on teaching-hospital mortality: the "July phenomenon" revisited. J Hosp Med. 2011, 6:389-394. 10.1002/jhm.917

9. Holmboe ES, Sherbino J, Long DM, et al.: The role of assessment in competency-based medical education . Med Teach. 2010, 8:676-682. 10.3109/0142159X.2010.500704

10. Gofton WT, Dudek NL, Wood TJ, Balaa F, Hamstra SJ: The Ottawa Surgical Competency Operating Room Evaluation (O-SCORE): a tool to assess surgical competence. Acad Med. 2012, 87:1401-1407.

10.1097/ACM.0b013e3182677805 